\title{
Treatment of whiplash-associated disorders - Part I: Noninvasive interventions
}

\author{
Anne Conlin BA\&Sc, Sanjit Bhogal BA, Keith Sequeira MD FRCPC, Robert Teasell MD FRCPC
}

\begin{abstract}
A Conlin, S Bhogal, K Sequeira, R Teasell. Treatment of whiplash-associated disorders - Part I: Noninvasive interventions. Pain Res Manage 2005;10(1):21-32.
\end{abstract}

BACKGROUND: A whiplash-associated disorder (WAD) is an injury due to an acceleration-deceleration mechanism at the neck. WAD represents a very common and costly condition, both economically and socially. In 1995, the Quebec Task Force published a report that contained evidence-based recommendations regarding the treatment of WAD based on studies completed before 1993 and consensusbased recommendations.

OBJECTIVE: The objective of the present article - the first installment of a two-part series on interventions for WAD - is to provide a systematic review of the literature published between January 1993 and July 2003 on noninvasive interventions for WAD using metaanalytical techniques.

METHODS OF THE REVIEW: Three medical literature databases were searched for identification of all studies on the treatment of WAD. Randomized controlled trials (RCTs) and epidemiological studies were categorized by treatment modality and analyzed by outcome measure. The methodological quality of the RCTs was assessed. When possible, pooled analyses of the RCTs were completed for meta-analyses of the data. The results of all the studies were compiled and systematically reviewed.

RESULTS: Studies were categorized as exercise alone, multimodal intervention with exercise, mobilization, strength training, pulsed magnetic field treatment and chiropractic manipulation. A total of eight RCTs and 10 non-RCTs were evaluated. The mean score of methodological quality of the RCTs was five out of 10. Pooled analyses were completed across all treatment modalities and outcome measures. The outcomes of each study were summarized in tables.

CONCLUSIONS: There exists consistent evidence (published in two RCTs) in support of mobilization as an effective noninvasive intervention for acute WAD. Two RCTs also reported consistent evidence that exercise alone does not improve range of motion in patients with acute WAD. One RCT reported improvements in pain and range of motion in patients with WAD of undefined duration who underwent pulsed electromagnetic field treatment. Conflicting evidence in two RCTs exists regarding the effectiveness of multimodal intervention with exercise. Limited evidence, in the form of three non-RCTs, exists in support of chiropractic manipulation. Future research should be directed toward clarifying the role of exercise and manipulation in the treatment of WAD, and supporting or refuting the benefit of pulsed electromagnetic field treatment. Mobilization is recommended for the treatment of pain and compromised cervical range of motion in the acute WAD patient.

Key Words: Exercise; Manipulation; Mobilization; Multimodal intervention; Review; Whiplash-associated disorders

\section{Traitement des séquelles du syndrome du coup de fouet - Partie I : Interventions non effractives}

HISTORIQUE : Le syndrome du coup de fouet (SCF) est une blessure causée par un phénomène mécanique d'accélération-décélération affectant le cou. Le SCF représente un problème de santé très courant et coûteux, tant sur le plan économique que social. En 1995, un groupe de travail québécois a publié un rapport qui contenait des recommandations au sujet du traitement du SCF fondées sur des preuves tirées d'études effectuées avant 1993, de même que des recommandations consensuelles. OBJECTIF : L'objectif du présent article, premier d'une série de deux sur le SCF, vise à faire une revue systématique de la littérature publiée entre janvier 1993 et juillet 2003 sur les interventions non effractives appliquées à ce type de problème par le biais de méta-analyses.

MÉTHODES D'ANALYSE : Trois bases de données de la littérature médicale ont été interrogées pour recenser toutes les études qui ont porté sur le traitement du coup de fouet. Les essais contrôlés randomisés (ECR) et les études épidémiologiques relevés ont été catégorisés par modalité thérapeutique et analysés selon les paramètres mesurés. La qualité méthodologique des essais randomisés et contrôlés a été évaluée. Dans la mesure du possible, des analyses regroupées de ces essais ont été effectués à des fins de méta-analyse des données. Les résultats de toutes les études ont été compilés et analysés de façon systématique.

RÉSULTATS : Les études ont été classées selon qu'il s'agissait d'exercices seulement, d'interventions multimodales avec exercices, de mobilisation, de renforcement, de traitement par champ magnétique pulsé ou de chiropraxie. En tout, huit ERC et dix essais d'un autre type ont été analysés. Le score moyen des ERC pour la qualité méthodologique a été de 5 sur 10. Les analyses regroupées ont été effectuées pour toutes les modalités thérapeutiques et mesures paramétriques. Les résultats de chaque étude ont été résumés dans des tableaux.

CONCLUSION : Deux ERC concluent aux bienfaits de la mobilisation comme intervention non effractive pour le SCF aigu. Deux ERC ont aussi signalé que l'exercice seul n'améliorait pas l'amplitude de mouvement chez les patients victime d'un SCF aigu. Un ERC a fait état d'améliorations de la douleur et de la mobilité chez les patients victimes d'un SCF de durée indéterminée et qui ont subi un traitement par champ électromagnétique pulsé. Des résultats divergents sont présentés dans deux essais randomisés et contrôlés au sujet de l'efficacité des interventions multimodales avec exercice. Des preuves restreintes tirées d'essais ni randomisés ni contrôlés appuient les manipulations chiropratiques. Les recherches à venir devraient être orientées vers la clarification du rôle de l'exercice et de la manipulation dans le traitement du SCF et tenter de vérifier s'il y a ou non des avantages à utiliser le champ électromagnétique pulsé. La mobilisation est recommandée pour le traitement de la douleur et pour les problèmes de mobilité cervicale suite au SCF. 
W hiplash-associated disorders (WAD) represent a significant public health problem and socioeconomic burden throughout the industrialized world. In a benchmark review of the scientific literature and expert opinions, the Quebec Task Force (QTF) defined WAD as "an acceleration-deceleration mechanism of energy transfer to the neck ... [which] may result in bony or soft tissue injuries (whiplash), which may in turn lead to a variety of clinical manifestations" (1). Whiplash is a common injury, with an incidence of approximately 3.8 cases per 1000 population per year (2). While the prognosis for the majority of patients is good, with most studies reporting permanent disability in only $6 \%$ to $18 \%$ of patients (3), whiplash is a potentially debilitating and costly injury. The economic costs associated with WAD, including medical care, disability, sick leave and lost work productivity, total approximately $\$ 3.9$ billion annually in the United States; this figure rises to more than $\$ 29$ billion when litigation costs are considered $(4,5)$.

A variety of interventions have been used to treat patients suffering from WAD, yet many of these interventions have not undergone sufficient clinical trials to confirm their effectiveness (6). The QTF itself concluded that the scientific evidence published before 1993 regarding whiplash was "sparse and generally of unacceptable quality" (1) and the QTF had to rely on consensus opinion for the majority of its mandated treatment recommendations. Yet, in the years since the review of the literature by the QTF, many new scientific and nonscientific studies regarding noninvasive, medical and surgical interventions for WAD have been published. The objective of this review is to identify and evaluate the literature on treatment of acute and chronic whiplash injury that has been published since the completion of the literature review by the QTF in January 1993, and to provide recommendations for clinical practice and future research. The present review, the first in a two-part series, evaluates noninvasive interventions for WAD. In part II (pages 33-40), medical and surgical interventions are reviewed.

\section{METHODS}

\section{Study identification and selection}

The MEDLINE and CINAHL databases and the Cochrane Central Register of Controlled Trials (CENTRAL) were searched for studies on the treatment and rehabilitation of WAD published between 1993 and 2003. The MEDLINE search key words included "whiplash injury" and "therapy" or "rehabilitation" or "drug therapy" or "radiotherapy", and the limits were English, human and subjects older than 18 years of age. The CINAHL search key words were "whiplash injury" and "rehabilitation" or "therapy" or "diet therapy" or "drug therapy" or "surgery", with the limits of English and age greater than 18. The CENTRAL was searched using the term "whiplash injury" and the limits of English and age over 18 were applied.

Articles identified through the database searches were included in the review if the purpose of the article was to study the effect of a specific, clearly defined treatment protocol on improvement of WAD secondary to motor vehicle collision. Randomized controlled trials (RCTs) and epidemiological studies, including cohorts, casecontrol studies and case series, were included in this review. An RCT is an experiment in which subjects in a population are randomly allocated into groups to receive or not receive a therapeutic intervention and the subjects are prospectively studied to measure the outcome of interest. A cohort study is a nonrandomized epidemiological study that involves identifying two groups of subjects, one that received the treatment and one that did not, and following the groups to measure the outcome of interest. A case-control study is a retrospective epidemiological study which involves identifying subjects who have the outcome of interest (cases) and subjects without the same outcome (controls), and then reviewing the subjects to determine which ones had the treatment of interest. A case series is an epidemiological report on a series of patients with a treatment of interest. No control group is reported. Meta-analyses, reviews, abstracts, letters and case reports of single patients were read but excluded. Studies were not excluded on the basis of treatment protocol, outcome measure or quality assessment.

The MEDLINE search identified 88 articles, of which 20 with met the inclusion criteria. Eighty-five articles were found through CINAHL, including six that were initially identified through the MEDLINE search. Four of the remaining articles met the inclusion criteria. The CENTRAL search yielded 43 articles, of which 11 were previously identified and two met the inclusion criteria. Finally, three studies that were cited in review articles and the included articles but not identified through the three databases were also retrieved, bringing the total number of clinical trials to 29 .

After all the clinical trials on the treatment of WAD were identified, three categories of interventions were developed: noninvasive interventions, medical interventions and surgical interventions. A total of 18 studies on noninvasive interventions were identified, including eight RCTs and 10 non-RCTs. Eleven studies on medical- and surgical-based interventions were included in the review (see part II, pages 33-40). Noninvasive interventions were subcategorized as physiotherapy exercise alone, multimodal treatment including physiotherapy exercise, patient mobilization, strength training, pulsed magnetic field treatment and chiropractic manipulation.

Studies were selected for meta-analyses if four criteria were met. First, each study had to meet the definition of an RCT. Second, the studies had to assess the difference between one treatment and no treatment, one treatment and a placebo or sham treatment, or between two treatments. Dose-escalating studies were not included. Third, each study had to report the results of at least one common type of outcome measure for the calculation of a pooled effect size that incorporated the data from at least two studies. Fourth, the duration of WAD injury was used to determine appropriate pooling of subject data for meta-analysis. Acute WAD was defined as any injury of less than three months duration, while chronic WAD was injury of more than three months. Studies that did not meet the inclusion criteria for meta-analysis were categorized, reviewed and summarized.

\section{Data abstraction}

The review process consisted of four parts: abstraction of data from each study regarding methodology, outcome measures, results and final conclusions; assessment of quality of the included RCTs; meta-analysis where inclusion criteria for meta-analysis were met; and summary of the findings and evidence in support of each treatment modality.

A single reviewer (AC) abstracted the data from each of the included RCTs using a predetermined data abstraction form. The information sought included sample population, subject inclusion and exclusion criteria, follow-up time period and outcome measures. The outcome measures were categorized as pain measures, physical measures, and function/coping measures. The pain measures included the Visual Analog Scale out of 10 or 100, the Pain Disability Index, the McGill Pain Questionnaire and subjective reports of pain. The 
TABLE 1

The Physiotherapy Evidence Database criteria

1. Subjects were randomly allocated to groups No/Yes

2. Allocation was concealed

No/Yes

3. The groups were similar at baseline regarding the most important prognostic indicators

4. There was blinding of all subjects

No/Yes

5. There was blinding of all therapists who administered the therapy

6. There was blinding of all assessors who measured at least one key outcome

7. Measures of at least one key outcome were obtained from more than $85 \%$ of the subjects initially allocated to groups

8. All subjects for whom outcome measures were available No/Yes received the treatment or control condition as allocated or, where this was not the case, data for at least one key outcome was analyzed by 'intention to treat'

9. The results of between-group statistical comparisons are No/Yes reported for at least one key outcome

10. The study provides both point measures and measures No/Yes of variability for at least one key outcome

Data from reference 7

physical measures included cervical range of motion (flexion, extension, left and right lateral flexion, and left and right rotation), kinesthetic sensibility and head posture. The function/coping measures included the Self-Efficacy Score, Vernon-Mior Score, sick-leave profile, self-reported psychological distress and self-reported ability to complete activities of daily living.

Two independent evaluators (AC and SB) evaluated the quality of the RCTs according to the Physiotherapy Evidence Database (PEDro) standardized rating scale, a validated tool used for the assessment of the quality of RCTs (7). The PEDro scale (Table 1) consists of a list of 10 equally weighted criteria for quality assessment of RCTs. Raters were blinded to each other's results until all studies were assessed. Any discrepancies in the assessment of the articles were resolved by discussion between the reviewers until consensus was reached.

\section{Statistical analysis}

The RCT results were analyzed to compare activation-based interventions with their control treatments. Data on the outcomes of each trial were pooled to arrive at an overall estimate of the effectiveness of the procedure. Analyses were based on the data provided at the end of the follow-up period. Subgroup analyses were attempted to determine the effect of each treatment modality on various outcomes of interest. For continuous data, including mean scores and mean change in scores, the results were presented as weighted mean differences (WMD), where the difference between the treatment group and the control group was weighted by the inverse of the variance. For dichotomous outcomes, results were presented as an OR or RR. Fixed effects models were used where statistical homogeneity was demonstrated $(\mathrm{P}>0.05)$.

Evidence for and against all treatment protocols was summarized in tables. The summary tables identify treatments by category and duration of WAD injury. The findings of all RCTs within a given treatment category are reported. For treatment categories for which no RCTs have been published, the results of all reported epidemiological studies are summarized.
TABLE 2

The Physiotherapy Evidence Database (PEDro) quality assessment scores for randomized controlled trials on noninvasive interventions

\begin{tabular}{|c|c|c|c|c|c|c|c|}
\hline \multirow[b]{2}{*}{ Authors, year } & \multicolumn{7}{|c|}{ PEDro criteria } \\
\hline & RA CA & BS SB & B TB AB & OM & ITT BC & PVM & Total \\
\hline $\begin{array}{l}\text { Soderlund and Lindberg, } \\
2001 \text { (11) }\end{array}$ & $\sqrt{ }$ & $\sqrt{ }$ & & $\sqrt{ }$ & $\sqrt{ }$ & $\sqrt{ }$ & 6 \\
\hline Borchgrevink et al, 1998 (14) & $\sqrt{ }$ & $\sqrt{ }$ & $\sqrt{ }$ & $\sqrt{ }$ & $\sqrt{ }$ & $\sqrt{ }$ & 6 \\
\hline Provinciali et al, 1996 (12) & $\sqrt{ }$ & $\sqrt{ }$ & $\sqrt{ }$ & $\sqrt{ }$ & $\sqrt{ }$ & $\sqrt{ }$ & 6 \\
\hline Bonk et al, 2000 (13) & $\sqrt{ }$ & $\sqrt{ }$ & & $\sqrt{ }$ & $\sqrt{ }$ & $\sqrt{ }$ & 5 \\
\hline Rosenfeld et al, 2000 (9) & $\sqrt{ }$ & $\sqrt{ }$ & & $\sqrt{ }$ & $\sqrt{ }$ & $\sqrt{ }$ & 5 \\
\hline Fitz-Ritson, 1995 (8) & $\sqrt{ } \sqrt{ }$ & & & $\sqrt{ }$ & & $\sqrt{ }$ & 4 \\
\hline Soderlund et al, 2000 (10) & $\sqrt{ }$ & $\sqrt{ }$ & & & $\sqrt{ }$ & $\sqrt{ }$ & 4 \\
\hline Thuile and Walzl, 2002 (15) & $\sqrt{ }$ & $\sqrt{ }$ & & & $\sqrt{ }$ & $\sqrt{ }$ & 4 \\
\hline
\end{tabular}

AB Assessor blinding; BC Between-group comparison; BS Baseline similarity of subjects; CA Concealed allocation; ITT Intention-to-treat analysis; OM Outcomes measures of $85 \%$ of subjects or more; PVM Point and variability measures; RA Random allocation; SB Subject blinding; TB Therapist blinding

\section{RESULTS}

\section{RCTs}

A total of eight RCTs examined noninvasive interventions (Table 2). Of these, three studied exercise alone (8-10), two studied exercise in conjunction with multimodal intervention $(11,12)$, and two compared mobilization with immobilization $(13,14)$ and one studied pulsed magnetic field treatments (15) (Table 3). The median methodology quality score was five, while the range was three to six (Table 2). The criteria of random allocation, baseline homogeneity of subjects, and between-group statistical comparison were commonly fulfilled. One study failed to demonstrate both baseline homogeneity of subjects and between-group statistical comparison (8). However, intention to treat analysis was not completed in any of the eight trials.

Rosenfeld et al (9) randomized patients to four groups: treatment initiated within $96 \mathrm{~h}$ versus treatment delayed for two weeks and active treatment (neck exercises 10 times per waking hour) versus standard treatment (active movements up to three times daily and optional use of a soft collar for comfort and immobility). Pain and range of motion was assessed initially and at six months. The study revealed that active treatment resulted in significant improvements in pain $(\mathrm{P}<0.001)$ but not range of motion. In addition, when active treatment was provided, it was better when it was provided early; when standard treatment was provided, it was better when it was provided late. However, other studies regarding physiotherapy exercises failed to demonstrate significant differences between treatment and control groups. Soderlund et al (10) compared the outcome of patients who completed additional exercises to improve kinesthetic sensibility and neck muscle coordination to patients who did not, and found no significant difference between the groups for improvement in pain, physical parameters or function at the six-month follow-up. Fitz-Ritson (8) compared pain disability among patients undergoing chiropractic manipulation and phasic movements about the eyes, head, neck and arms to patients receiving chiropractic care alone, but failed to provide a between-group analysis and offered no conclusions on the comparative efficacy of these treatments. 


\section{Conlin et al}

TABLE 3

Summary of randomized controlled trials

\begin{tabular}{|c|c|}
\hline $\begin{array}{l}\text { Authors, year } \\
\text { and country }\end{array}$ & Population and methods \\
\hline \multicolumn{2}{|l|}{ Exercise alone } \\
\hline $\begin{array}{l}\text { Fitz-Ritson, 1995, } \\
\text { United States (8) }\end{array}$ & $\begin{array}{l}\text { Thirty patients with a 12-week history of } \\
\text { whiplash injury were randomized to } \\
\text { two groups. The control group underwent } \\
\text { standard exercises (stretching, isometric, } \\
\text { isokinetic) for } 2 \text { weeks and chiropractic } \\
\text { therapy. The treatment group did "phasic } \\
\text { exercises" (including rapid eye-head-neck-arm } \\
\text { movements) for } 4 \text { weeks and chiropractic } \\
\text { therapy. }\end{array}$ \\
\hline
\end{tabular}

Rosenfeld et al, Ninety-seven consecutive patients with a 2000 , Sweden whiplash injury were randomized to

(9)

Soderlund et al 2000, Sweden

(10)

4 groups: early (within $96 \mathrm{~h}$ ) versus delayed (after 2 weeks) treatment and active versus standard treatment. Active treatment included small-range and amplitude-rotational movements of the neck 10 times every waking hour. Individual programs were added in cases that showed no improvement within 20 days. Patients receiving standard treatment were given written material advising rest for the first few weeks and then active movements 2 to 3 times daily, and were offered the use of a soft collar for comfort and immobility.

Fifty-nine symptomatic patients with acute whiplash injury (mean=20 days) were randomized to a regular treatment (control) group and an additional exercise treatment (treatment) group at their first presentation. Patients in the control group were instructed to complete arm, neck and breathing exercises twice daily; alternate rest with activity; protect the neck from cold; walk daily; maintain good posture; and avoid lifting. Patients in the treatment group completed additional exercises 3 times daily to improve kinesthetic sensibility and coordination of neck muscles.

\section{Multimodal intervention with exercise}

Soderlund and Lindberg, 2001, Sweden (11)
Thirty-three patients with whiplash injury of at least 3 months duration received regular primary care physiotherapy (control group) or physiotherapy with integrated cognitivebehavioural components (treatment group). Control group patients completed exercises to enhance muscular stabilization of neck, shoulder mobility, body posture and arm muscle strength; some also used pain-relieving methods including relaxation, TENS, acupuncture and heat. Experimental group treatment consisted of learning basic physical and psychological skills, application and generalization, and maintenance in accordance with a functionalbehavioural analysis.
Neck, head and shoulder pain and cervical range of motion were measured initially and at 6 months

Presence of pain, pain disability, cervical range of motion, head posture, kinesthetic sensibility, coping strategies and self-efficacy were evaluated initially at 3 months and 6 months.
Results

Each group showed significant improvement between initial and final assessments; no between-group analysis was reported.

\begin{abstract}
Active treatment reduced pain more than standard treatment $(P<0.001)$, but no differences were found in the improvement of cervical range of motion. When active treatment was provided, it was better when it was provided early, and if standard treatment was provided, it was better when it was administered late for reduction of pain $(P=0.04)$ and increasing cervical flexion $(P=0.01)$.
\end{abstract}

There was no significant difference between groups for improvement in pain, physical parameters or function at the final assessment.
Pain intensity and disability, cervical range of motion, head posture and global functioning were assessed at initially and at 3 months.
No differences were reported for pain intensity or disability, cervical range of motion or head posture. The experimental group reported better performance on activities of daily living at the 3-month follow-up.
Continued on next page 
Provinciali et al, Sixty patients with whiplash injury of less than 1996, Italy (12)

Mobilization

Bonk et al, 2000, Ninety-seven patients with whiplash injury Germany and of less than three days received active Canada (13)

\section{2 months were randomly allocated}

to an experimental group receiving multimodal treatment (relaxation training, active reduction of cervical and lumbar lordosis, massage and mobilization of cervical spine, eye fixation exercises, psychological support) or a control group (TENS, pulsed electromagnetic therapy, ultrasound, calcic iontophoresis with calcium chloride). Each group completed ten $1 \mathrm{~h}$ sessions over 2 weeks.
Pain intensity, cervical range of motion, self-rating scale of treatment efficacy and return to work delay were evaluated before treatment, after treatment, at 30 days and at 180 days.

\author{
There was greater improvement in the \\ multimodal treatment group in all \\ outcome measures except neck mobility \\ (pain $\mathrm{P}<0.001$, self-assessment of \\ outcome $P<0.001$, delay in returning to \\ work $P<0.001$ )
} The 47 patients of the treatment group received active and passive mobilization, postural exercise, and advice over 3 weeks; the remaining 50 patients were immobilized in a soft collar for 3 weeks.

Borchgrevink et al, Two hundred one patients with acute 1998, Norway (14) whiplash injury all received instructions for self-training exercises of the neck beginning on the first day of treatment and a 5-day prescription for a nonsteroidal anti-inflammatory drug. Patients were randomly assigned to "act-as-usual" group (no sick leave or collar) or an immobilized group (14 days of sick leave and collar use).

\section{Pulsed magnetic field treatments}

Thiule and Walzl, Ninety-two patients with whiplash injury of 2002, Austria (15) undefined period of time were randomized to two groups. The treatment group received diclofenac, tizanidine and pulsed magnetic field treatment twice daily for two weeks, while the control group received the medications alone.
Neck, head, shoulder and arm pain and cervical flexion, extension and rotation were assessed initially and after treatment.
Presence and intensity of neck, shoulder, head and arm pain and neck stiffness, and cervical range of motion were assessed at $1,2,3,6$ and 12 weeks.

At 3 weeks, active therapy patients had significantly less pain and improved neck ROM than collar patients. Treatment groups did not differ from healthy controls on symptom prevalence at 6 weeks for active therapy patients and at 12 weeks for collar treatment patients.

Pain intensity, pain localization, other associated symptoms, neurological clinical exam, shoulder and neck muscle function, and global improvement were evaluated at 2 weeks and 6 months.

co

\section{There was a significantly better outcome}

for the act-as-usual group for pain

intensity, neck stiffness, memory and

concentration. There was also a

significant reduction of symptoms from the time of intake to 24 weeks after the treatment period in both groups.
Patients receiving the magnetic field treatment had significantly less pain than controls $(P<0.03)$ and significantly greater range of motion $(P<0.05)$.

TENS Transcutaneous electrical nerve stimulation

Two RCTs assessed the effectiveness of exercise in conjunction with multimodal interventions. Provinciali et al (12) found that patients who received multimodal treatment consisting of relaxation training, cervical spine mobilization, fixation exercises and psychological support showed significantly greater improvement in pain $(\mathrm{P}<0.001)$, self-assessment of outcome $(\mathrm{P}<0.001)$ and delay in return to work $(\mathrm{P}<0.001)$ at 180 days compared with patients receiving physical interventions alone. However, Soderlund and Lindberg (11) found no significant differences in the outcome measures of pain intensity, pain disability, cervical range of motion, and head posture when they compared patients whose treatment plan included functional behavioural analysis with patients whose treatment plan did not.

Two noninvasive intervention studies compared mobilization to immobilization $(13,14)$. The studies reported that patients who did not use a soft collar for immobilization fared significantly better than those who did on outcome measures of pain, cervical range of motion (13), neck stiffness, memory and concentration (14).

One RCT (15) reported that pulsed magnetic field treatment was an effective form of treatment for WAD. Patients receiving this treatment had significantly less pain $(\mathrm{P}<0.03)$ and significantly greater range of motion $(\mathrm{P}<0.05)$ compared with controls (8).

Pooled analysis of RCTs

Pooled analysis was considered for the eight RCTs. Three of the RCTs were excluded from pooled analysis on the basis of failure to report standard deviations $(8,9,12)$. Pooled analysis was thus possible for five studies and a total of 850 patient data points $(10,11,13-15)$.

Categorically, active treatment was not found to be superior to control treatment on the outcome measure of degree of pain as measured by a variety of pain scales (WMD -1.10 , 95\% CI -1.18 to -1.02$)(10,11,14,15)$ (Figure 1$)$. However, 


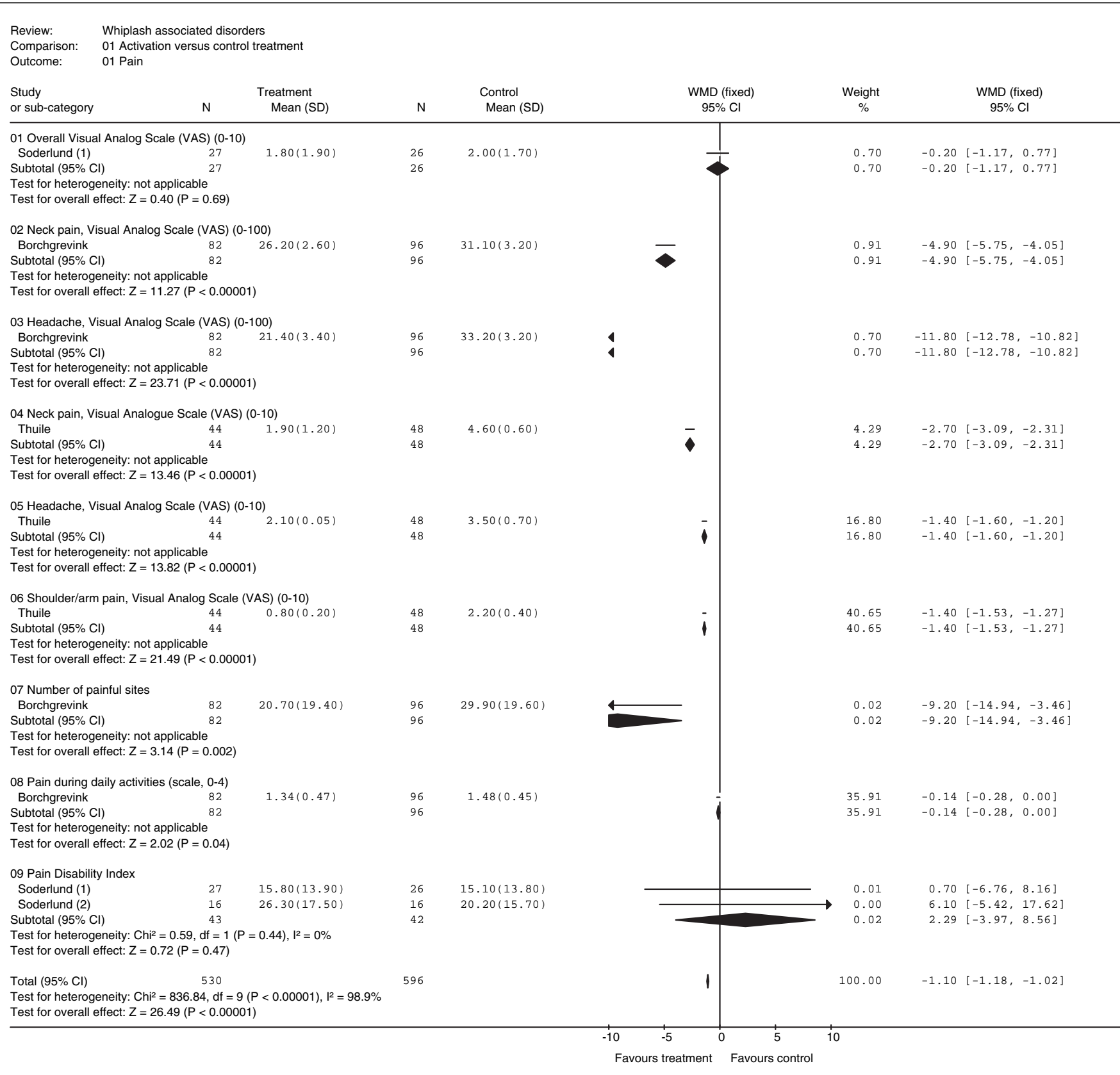

Figure 1) Active treatment versus control treatment: degree of pain. WMD Weighted mean difference. Soderlund (1) refers to reference 10 and Soderlund (2) refers to reference 11

pooled analysis for presence of pain at four anatomical areas as measured by Bonk et al (13) indicated that mobilization was superior to soft collar use (OR $0.56,95 \%$ CI 0.31 to 1.01 ) (Figure 2). As well, pooled analysis for the outcome measure of cervical range of motion across five studies (10,11,13-15) revealed that subjects undergoing noninvasive interventions had significantly greater improvement in cervical range of motion than did subjects in the control groups (WMD 4.70; 95\% CI 4.34 to 5.07 ) (Figure 3). Analysis of other physical outcome measures, including cervicothoracic posture and kinesthetic sensibility, demonstrated no significant difference $(\mathrm{P}=0.28)$ between control and treatment groups when the results of the 261 patients from two studies were pooled $(10,11)$ (Figure 4). Finally, pooled analysis was also completed for noninvasive treatments on the outcome measures of selfefficacy and other measures of function $(10,14)$; however, there was no significant difference between the control and treatment groups $(\mathrm{P}=0.72$ and $\mathrm{P}=0.92$, respectively) (Figures 5 and 6).

\section{Nonrandomized studies}

Ten nonrandomized studies assessed the impact of noninvasive treatment on outcome in whiplash patients. The populations and methods, outcome measures and results are summarized in Table 4.

Soderlund and Lindberg (16) conducted a multiple baseline design study of three patients with WAD of at least four months duration who underwent psychological and behavioural 


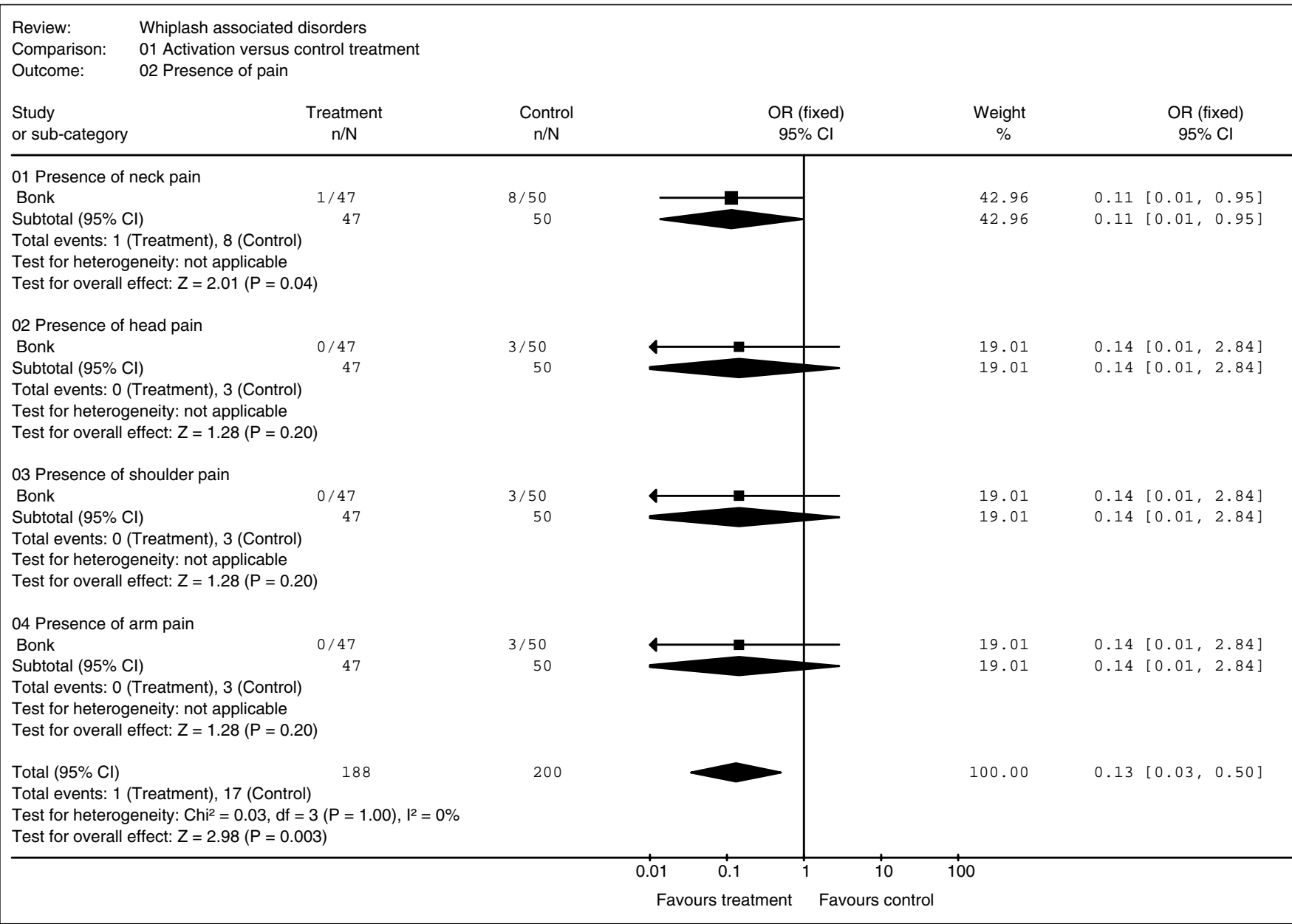

Figure 2) Active treatment versus control treatment: presence of pain. WMD Weighted mean difference

functional analyses and physiotherapy. Compared with the patients' baseline measures, all measures of pain intensity and cervicothoracic posture were significantly improved. Neck range of motion and self-efficacy scores also improved in two of three patients on completion of the multimodal intervention.

Heikkila and Astrom (17) assessed eight patients with chronic whiplash injury after completion of a six-week multidisciplinary rehabilitation program involving physical and occupational therapy, psychology and social work. Active head repositioning was significantly more precise after the rehabilitation program for cervical rotation and extension; however, no significant improvement was found on pain intensity as measured by the Visual Analog Scale.

In another study (18), patients with chronic WAD with temporomandibular disorder and patients with temporomandibular disorders alone underwent eight weeks of muscle exercises, counselling and splint stabilization. Compared with the control group, WAD patients had significantly more headaches, tender muscles, somatic complaints and psychological distress. As well, WAD patients showed improvement in the proportion of tender muscles, while the control group showed improvements on all outcome measures (18).

Two case series $(19,20)$ also documented the effectiveness of multimodal interventions with exercise on the outcome of WAD patients. Sterner et al (19) followed 90 patients with whiplash injury of undefined duration who completed a program consisting of hydrotherapy, body awareness therapy, ergonomics, pharmacology and pain education. At the sixmonth follow-up, pain intensity in the neck and upper back were significantly decreased $(\mathrm{P}=0.018)$. Vendrig et al (20) assessed 26 patients with WAD of six months duration or longer who completed a four-week treatment program to restore muscle strength, muscle endurance and aerobic fitness, and abolish inappropriate pain behaviour. When reassessed at six months, the patients demonstrated significant improvement on the measures of pain intensity, disability, somatic complaints and psychological symptoms.

Gennis et al (21) conducted a cohort study to assess the effectiveness of activation-based treatment by comparing the outcomes of WAD patients assigned to wear a soft collar following initial presentation to the emergency department. There was no significant difference between the groups on the measures of degree of pain, recovery, improvement or deterioration.

Goodman and Frew (22) assessed the effectiveness of exercise alone for the treatment of whiplash of varying duration by following 10 patients who underwent 18 strength-training sessions over six weeks. Patients demonstrated improvement in cervical range of motion and isometric strength, but the statistical significance of the improvement was not reported.

Three case series (23-25) assessed the impact of manipulation on various outcome measures in WAD patients. In one 


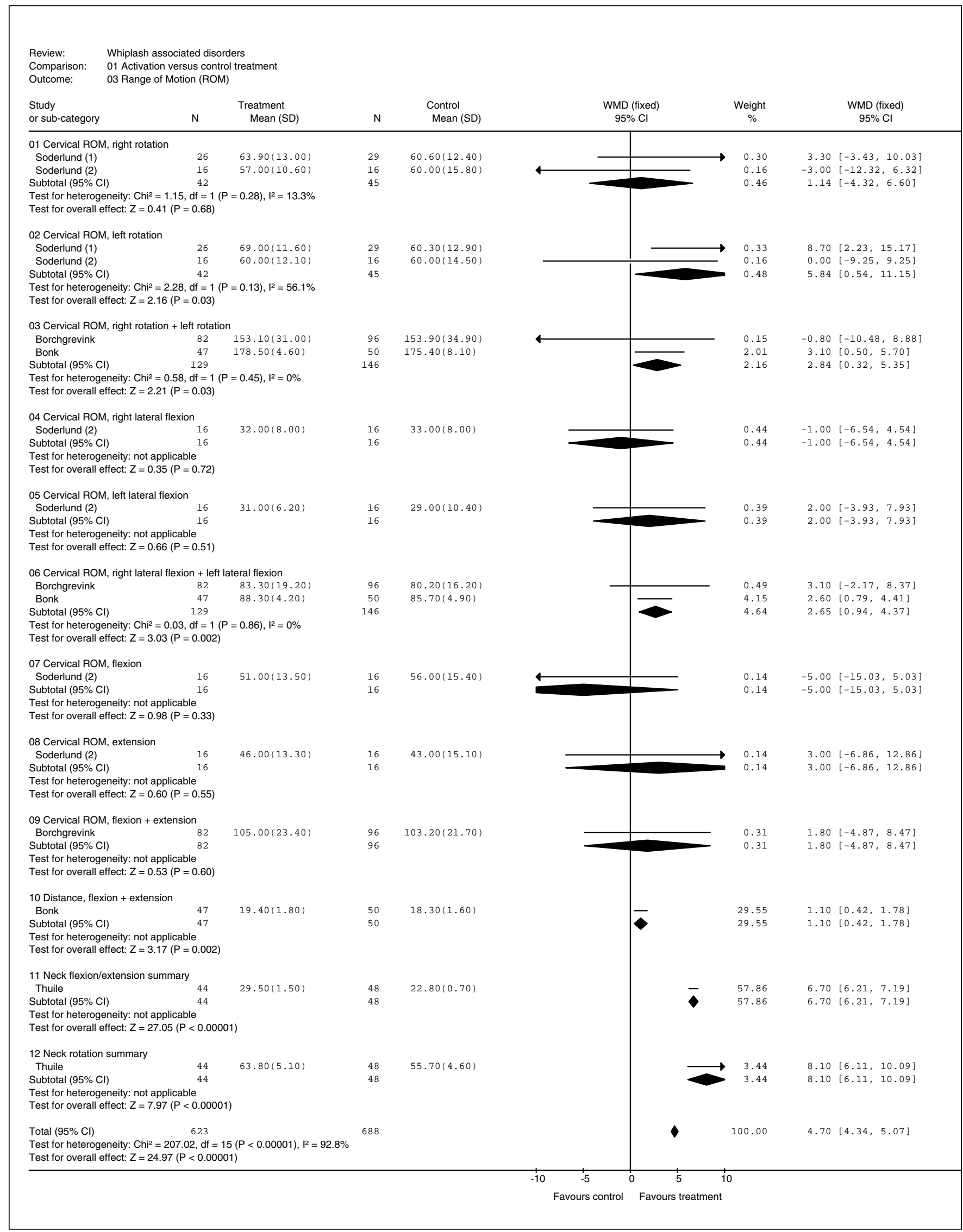

Figure 3) Active treatment versus control treatment: range of motion. WMD Weighted mean difference. Soderlund (1) refers to reference 10 and Soderlund (2) refers to reference 11 


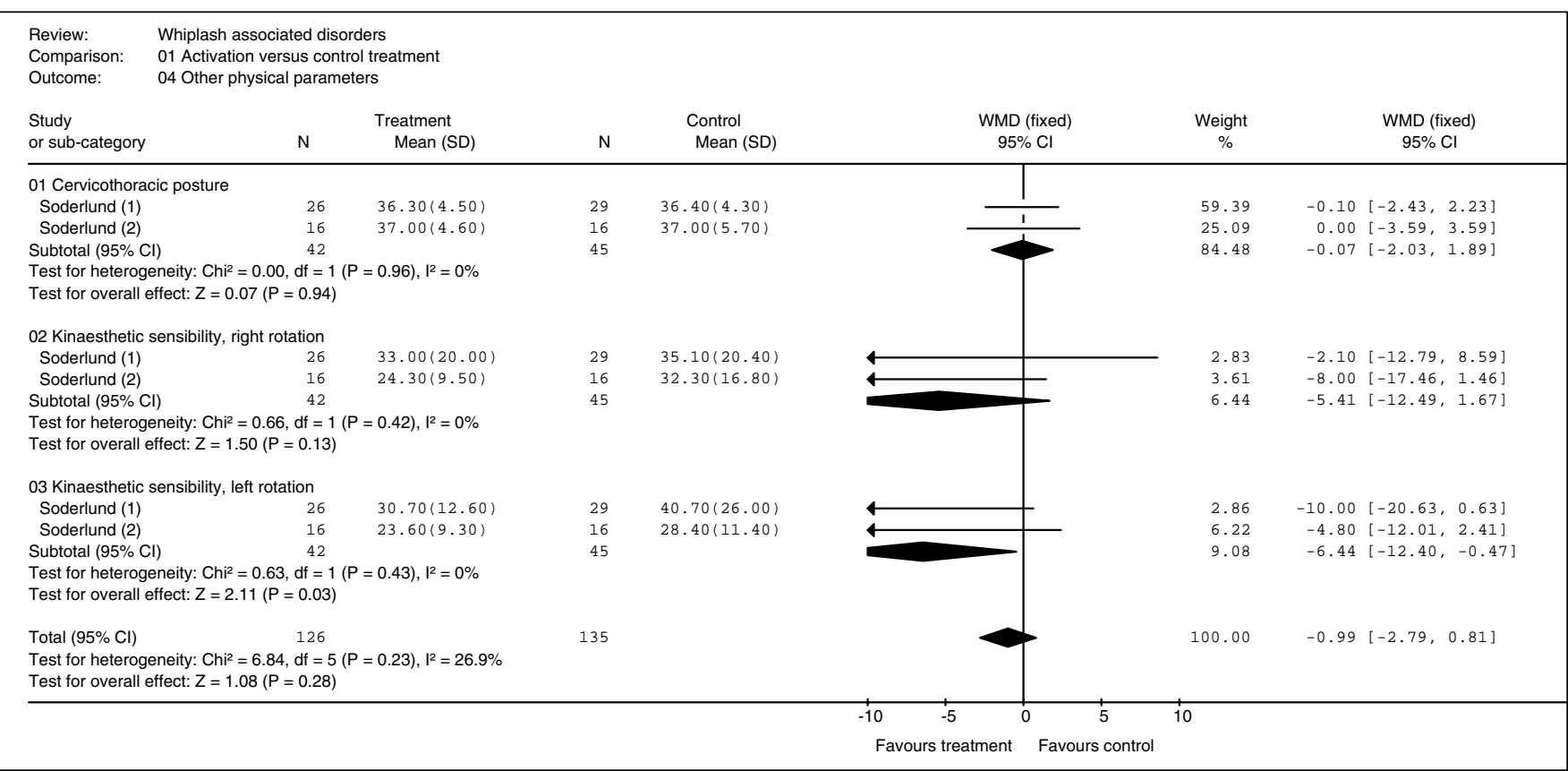

Figure 4) Active treatment versus control treatment: other physical parameters. WMD Weighted mean difference. Soderlund (1) refers to reference 10 and Soderlund (2) refers to reference 11

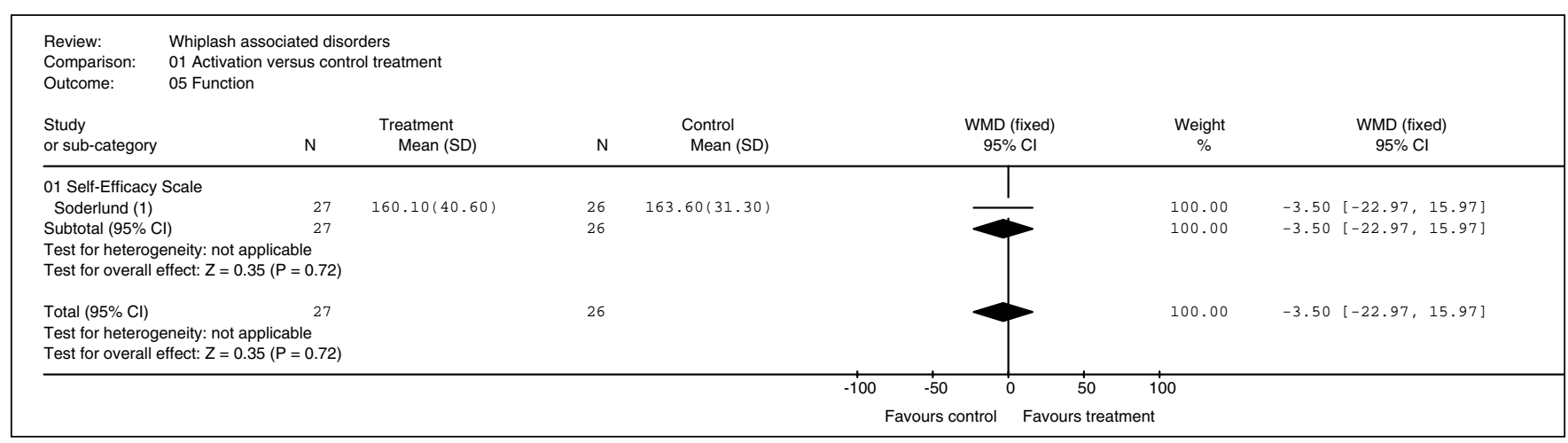

Figure 5) Active treatment versus control treatment: self-efficacy. WMD Weighted mean difference. Soderlund (1) refers to reference 10

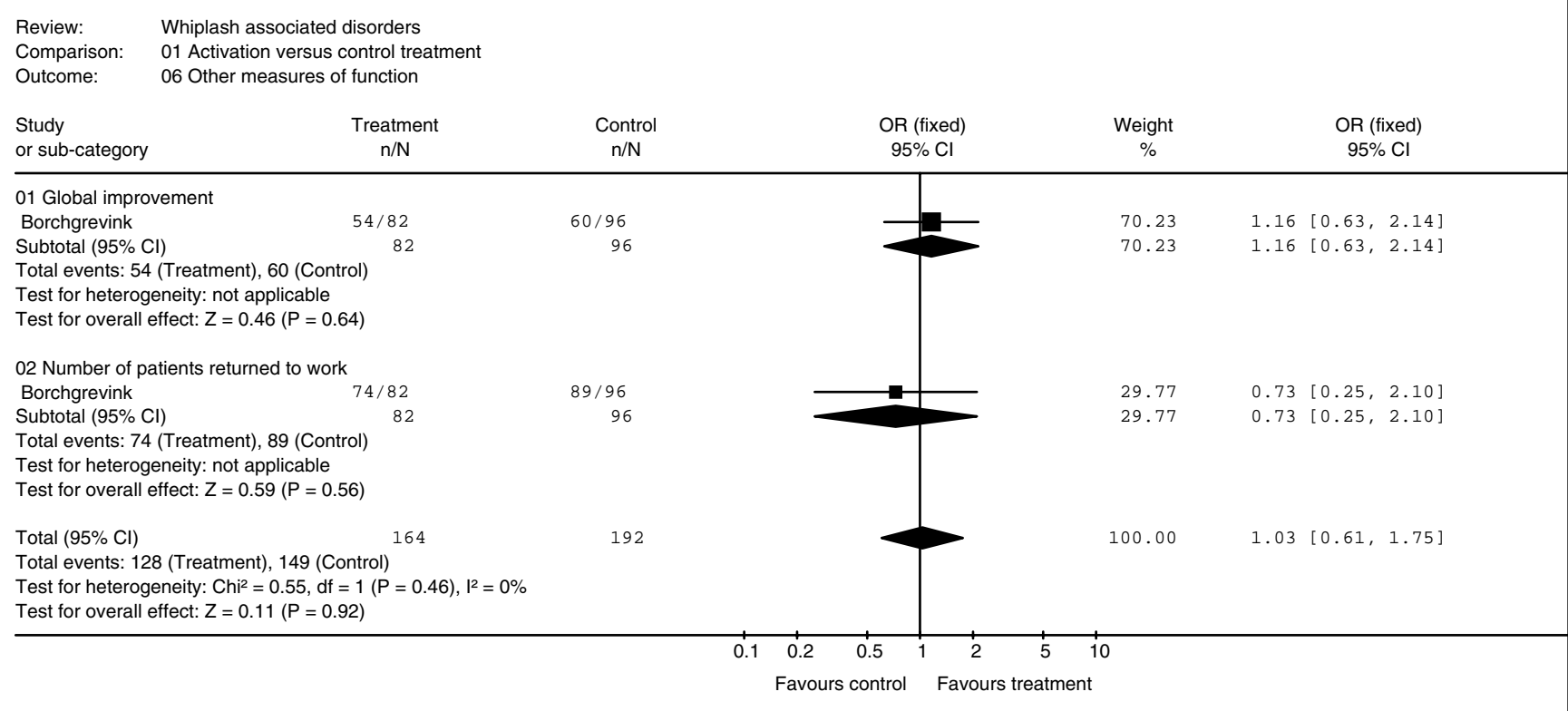

Figure 6) Active treatment versus control treatment: other measures of function. WMD Weighted mean difference 
TABLE 4

Summary of nonrandomized studies

Authors, year
and country $\quad$ Population and methods

Multimodal intervention with exercise

Soderlund and

Lindberg, 2001,

Sweden (16)

Multiple baseline design - Three patients

with persistent neck pain and stiffness for

at least 4 months following whiplash injury underwent psychological and physical functional behavioural analyses. Patients received individualized cognitive-behavioural treatment consisting of learning basic and applied skills, generalization and maintenance. Patients also had physiotherapy (not described).

Heikkila and Astrom, 1996,

Cohort - Eight patients with a 2- to 3-year

Sweden (17) history of whiplash injury participated in a six-week multidisciplinary rehabilitation program. Counselling was provided by physical and occupational therapists, psychologists and social workers; exercise programs were individualized and based on a behavioural therapy approach. Thirty-four healthy and uninjured subjects formed the control group.

Krogstad et al, Case control study - Sixteen patients with 1998, Norway (18) TMDs and whiplash injury were compared to 16 patients with TMD only. All had symptoms for 1 to 3 years.

Both groups had 8 weeks of conservative TMD treatment consisting of counselling, muscle exercises and a stabilization splint.

Sterner et al, Case series - Ninety subjects with whiplash 2001, Sweden (19) injuries of undefined duration entered a multimodal 5- and 8-week rehabilitative program (15 to 16 days total). The program included group and individual sessions on ergonomics, physical activity with hydrotherapy, body awareness therapy, pharmacology and education in pain and the psychological consequences of pain.

Vendrig et al, 2000, Case series - Twenty-six patients with Netherlands (20) whiplash injury of at least 6 months duration entered a daily, 4-week, multimodal treatment program intended to abolish inappropriate pain behaviour, restore muscle strength and endurance, and enhance aerobic fitness.

The assessment and treatment team consisted of orthopedic surgeons, neurologists, psychologists, occupational therapists and physical therapists.

\section{Mobilization}

Gennis et al, 1996, Cohort - Adults with whiplash injury following United States (21) an automobile crash who were treated at an urban emergency department were assigned to wear a soft collar (92 patients) or no collar (104 patients).

Outcome measures

Results

Pain intensity and disability, cervicothoracic posture, neck range of motion, coping, and self-efficacy were measured 6 times during the 1 week baseline period and during each treatment session.

Cervicobrachial pain, kinesthetic sensibility, stress tolerance and activities of daily living were assessed during the first and sixth week for the treatment group, and during the fourth and eighth week for the control group.

Headache frequency and intensity, clinical exam, somatic complaints and psychological distress were assessed at the start of treatment and 8 weeks later.

Pain, symptoms, quality of life, functioning and sick leave were assessed initially, immediately after the program and at 6 months.

Pain intensity; medication use; self-reported disability; somatic, cognitive and psychological symptoms; paramedical treatment; and return to work were assessed at 6 months.

Pain intensity and categorical pain (more, same, less or none) was evaluated initially and at 6 weeks.
All patients showed decreased pain intensity scores and improvements in cervicothoracic posture. One patient, whose baseline neck range of motion score was normal at baseline, showed no improvement of neck range of motion; the other two patients showed improved range of motion. One patient had a worse disability score at the end of treatment, while two patients had better scores. No other statistics were reported.

Active head positioning was significantly less accurate $(\mathrm{P}<0.001)$ in whiplash subjects compared with the control group. Repositioning was significantly more precise in whiplash subjects after the 6 -week rehabilitation program (rotation $\mathrm{P}=0.04$, extension $\mathrm{P}=0.005$ ). No significant differences were found on Visual Analogue Scale between testing sessions

Compared to TMD-only patients, WAD patients had significantly more headaches $(P<0.001)$, more tender muscles $(P=0.002)$, more somatic complaints $(P<0.002)$ and greater psychological distress $(P<0.003)$ at follow-up. WAD patients showed improvement in the proportion of tender muscles.

Pain intensity in neck and upper back were significantly decreased at 6 months $(P=0.018, P=0.011$, respectively). Patients indicated an increased ability to cope with and control pain, and a somewhat increased ability to cope with psychological aspects (significance not reported). Scales also showed that most patients were slightly depressed.

Pain intensity, disability, somatic complaints, cognitive complaints and psychological symptoms were significantly improved $(\mathrm{P}<0.01)$. High proportions of patients ( $58 \%$ to $92 \%$ ) reported complete or partial return to work and no use of analgesics or paramedical treatment.
No significant difference between the groups was found for degree of pain, recovery, improvement or deterioration. 
Strength training
Goodman and

Frew, 2000,

Canada (22)
Case series - Ten patients with whiplash injury Fu
of varying duration underwent 18 strengthtraining sessions over 6 weeks. The program consisted of graduated resistance exercises for neck flexion, extension, right and left rotation, and right and left lateral flexion. Patients performed 3 sets of 10 repetitions with weights starting at 4 ounces and increasing to at most 20 pounds, an isotonic exercise.

\section{Manipulation}

Suter et al, 2002, Case series - Twenty-three patients with Canada (23) whiplash injury of 3 to 6 weeks duration underwent cervical spinal manipulation treatment.

\section{McCoy and Case series - Fifty-seven patients with McCoy, 1997, whiplash injury of varying duration United States (24) (range 1 to 24 months) underwent subluxation-based chiropractic care to the point of maximum chiropractic improvement for an average of 29 weeks (range 2 to 114 weeks).}

Woodward et al, Case series - Twenty-eight patients with 1996, United whiplash injury of at least 3 months duration Kingdom (25)
Cervical range of motion and muscle strength during maximal effort neck flexion/extension and arm abduction/adduction were before and after treatment.

Neck pain, cervical range of motion, atlas/axis angles, shoulder muscle strength and self-reported disability were assessed before and after treatment.
Across all 6 directions, range of motion improved by a mean of $28 \%$ ( $21 \%$ to $45 \%$ ) and isometric strength improved by a mean of $245 \%$ ( $197 \%$ to $302 \%)$. Statistical significance was not reported.

\section{Improvement was reported on al outcome measures; statistical significance not disclosed.}

Neck pain and cervical flexion and extension showed statistically significant improvement.

\section{Reports of pain, analgesics usage, and function were used to classify patients into four categories before and after treatment. Follow-up period undefined.}

\author{
A significant proportion $(93 \%, \mathrm{P}<0.001)$ \\ of patients showed categorical \\ improvement following treatment
} of spinal manipulation, proprioceptive neuromuscular facilitation and cryotherapy.

TMD Temporomandibular disorder; WAD Whiplash-associated disorder

study (23), 23 patients with whiplash injury of three to six weeks' duration underwent cervical spinal manipulation. Patients demonstrated improvement in cervical range of motion and neck and arm muscle strength, but the statistical significance was not reported. McCoy and McCoy (24), however, found significant improvement in neck pain and cervical flexion and extension among 57 patients with WAD of varying duration who underwent subluxation-based chiropractic care to the point of maximal improvement. As well, Woodward and colleagues (25) found that a significant proportion of patients $(\mathrm{P}<0.001)$ with WAD of at least three months had categorical improvement based on reports of pain, analgesics usage, and function following spinal manipulation, proprioceptive neuromuscular facilitation and cryotherapy.

\section{SUMMARY OF EVIDENCE}

A total of 18 RCTs and epidemiological studies measured outcomes in patients with WAD following noninvasive interventions. The treatment protocols and evidence are summarized in Table 5.

\section{DISCUSSION}

In 1990, La Société de l'assurance automobile du Québec (SAAQ), the provincial government no-fault insurance carrier in the Canadian province of Quebec, commissioned a panel of expert clinicians and epidemiologists to make public policy recommendations on the prevention and treatment of whiplash-associated disorders (1). The stated reasons for commissioning the study reflected concerns with both the magnitude of the problem of WAD and the paucity of evidence-based interventions to effectively manage it. After an exhaustive review of the literature on the treatment of

\section{TABLE 5}

Summary of evidence for noninvasive interventions

\begin{tabular}{|c|c|c|}
\hline Intervention & Duration of WAD & Summary of evidence \\
\hline Exercise & Acute WAD only & $\begin{array}{l}\text { Two RCTs found no improvement } \\
\text { in cervical range of motion. } \\
\text { Discrepant findings } \\
\text { in two RCTs on pain. }\end{array}$ \\
\hline $\begin{array}{l}\text { Multimodal with } \\
\text { exercise }\end{array}$ & $\begin{array}{l}\text { Acute and } \\
\text { chronic WAD }\end{array}$ & $\begin{array}{l}\text { Discrepant findings in two RCTs } \\
\text { on measures of pain for acute } \\
\text { and chronic WAD. Similar } \\
\text { discrepancy among } 4 \text { non-RCTs } \\
\text { for chronic WAD. }\end{array}$ \\
\hline Mobilization & Acute WAD only & $\begin{array}{l}\text { Two RCTs found improvement } \\
\text { in measures of pain and cervical } \\
\text { range of motion for acute WAD. }\end{array}$ \\
\hline $\begin{array}{l}\text { Pulsed } \\
\text { magnetic field } \\
\text { treatment }\end{array}$ & Undefined & $\begin{array}{l}\text { One RCT reported improvement on } \\
\text { pain and range of motion among } \\
\text { subjects treated with pulsed } \\
\text { magnetic fields. }\end{array}$ \\
\hline $\begin{array}{l}\text { Chiropractic } \\
\text { manipulation }\end{array}$ & $\begin{array}{l}\text { Acute, chronic, } \\
\text { and varying } \\
\text { duration of WAD }\end{array}$ & $\begin{array}{l}\text { Three non-RCTs showed } \\
\text { improvement in measures of } \\
\text { pain, range of motion and } \\
\text { function in WAD of varied duration. }\end{array}$ \\
\hline
\end{tabular}

RCT Randomized controlled trial; WAD Whiplash-associated disorder

WAD, the members of the QTF concluded that the scientific evidence was "sparse and generally of unacceptable quality" (1). Nevertheless, the QTF outlined evidence-based recommendations for clinical practice as well as extensive recommendations for research.

The QTF found insufficient evidence to assess the independent contribution of exercise in the treatment of WAD. 
Since the QTF report, two RCTs have been published that provide evidence that exercise does not improve range of motion in acutely injured WAD patients $(9,10)$. However, these RCTs also give conflicting evidence regarding the utility of exercise for the treatment of pain in acute WAD. Other studies exist regarding the independent contribution of exercise, but the methodologies render the findings noncontributory.

The QTF also found weak cumulative evidence to restrict the prescription of cervical collars and rest as interventions for WAD, as well as weak evidence to support mobilization. Since 1993, two RCTs $(13,14)$ have been published which substantiate the QTF findings. These studies indicate that mobilization combined with a lack of soft collar use is an effective intervention for pain and cervical range of motion in the acutely injured WAD patient. A third RCT found no difference in the outcome of mobilized and immobilized patients with WAD (21); however, due to the poor methodological quality of this trial, the validity of the results is questionable and the evidence is subsequently interpreted among the non-RCT studies.

One study was cited by the QTF regarding the utility of pulsed magnetic field treatment; however, due to the lack of statistically significant differences between the treatment groups, no recommendations for or against pulsed magnetic field treatments were made. This review identified one RCT supporting pulsed electromagnetic field treatment for improvement in pain and range of motion. However, the authors failed to specify the duration of the injury of the patients in the study, and thus, the implications for clinical practice are unclear.

Studies regarding the efficacy of a single chiropractic manipulation in the treatment of WAD were discussed by the QTF, but due to the design of the studies, no recommendations were made. Since 1993, three non-RCTs (23-25) demonstrating improvements in the measures of pain, range of motion and function in WAD of varied duration have been published. However, because of the lack of methodological rigour of these non-RCTs, only limited evidence exists in support of chiropractic manipulation, and future research is recommended.

Four RCTs that evaluated multimodal intervention with exercise were identified by the QTF. While the QTF criticized each study for failing to evaluate the independent effect of exercise, it nonetheless concluded that the cumulative evidence at that time suggested that active exercises as part of a multimodal intervention can be beneficial. In the multimodal studies reviewed here, conflicting evidence was identified in two RCTs $(11,12)$ and four non-RCTs $(16-19)$ on the outcome measure of pain.

Overall, mobilization appears to be the most effective noninvasive form of intervention for the treatment of both pain and cervical range of motion in the acutely injured WAD patient. As well, substantiated evidence exists to suggest that exercise does not improve range of motion in acute WAD. For all other noninvasive interventions, evidence regarding their effectiveness ranges from limited to conflicting. However, since the completion of the literature review by the QTF in 1993, multiple studies have also been published which assess the utility of medical and surgical interventions. Part II (pages 33-40) of this series provides a review of these interventions and offers further recommendations for clinical practice and future research.

\section{REFERENCES}

1. Spitzer WO, Skovron ML, Salmi LR, et al. Scientific monograph of the Quebec Task Force on Whiplash-Associated Disorders: Redefining "whiplash" and its management. Spine 1995;20(Suppl 8):1S-73S.

2. Barnsley L, Lord S, Bogduk N. The pathophysiology of whiplash. In: Spine: State of the Art Reviews. Philadelphia: Hanley \& Belfus, 1998; 12:209-42.

3. Lovell ME, Galasko CSB. Whiplash disorders - A review. Injury 2002;33:97-101.

4. Lord SM, Barnsley L, Wallis BJ, Bogduk N. Chroinc cervical zygapophysial joint pain after whiplash: A placebo-controlled prevalence study. Spine 1996;21:1737-44.

5. Freeman MD, Croft AC, Rossignol AM, Weaver DS, Reiser M. A review and methodologic critique of the literature refuting whiplash syndrome. Spine 1999;24:86-96.

6. Bogduk N. An overview of the International Congress on Whiplash Associated Disorders. Pain Res Manage 2003;8:103-6.

7. Maher CG, Sherrington C, Herbert RD, Moseley AM, Elkins M. Reliability of the PEDro scale for rating quality of randomized controlled trials. Phys Ther 2003;83:713-21.

8. Fitz-Ritson D. Phasic exercises for cervical rehabilitation after "whiplash" trauma. J Manipulative Physiol Ther 1995;18:21-4.

9. Rosenfeld M, Gunnarsson R, Borenstein P. Early intervention in whiplash-associated disorders. Spine 2000;25:1782-7.

10. Soderlund A, Olerud C, Lindberg P. Acute whiplash-associated disorders (WAD): The effects of early mobilization and prognostic factors in long-term symptomatology. Clin Rehab 2000;14:457-67.

11. Soderlund A, Lindberg P. Cognitive behavioural components in physiotherapy management of chronic whiplash associated disorders (WAD) - a randomised group study. Physiother Theory Pract 2001;17:229-38.

12. Provinciali L, Baroni M, Illuminati L, Ceravolo MG. Multimodal treatment to prevent the late whiplash syndrome. Scand J Rehabil Med 1996;28:105-11.

13. Bonk AD, Ferrari R, Giebel GD, Edelmann M, Huser R. Prospective, randomized, controlled study of activity versus collar, and the natural history for whiplash injury, in Germany. J Musculoskelet Pain 2000;8:123-32.

14. Borchgrevink GE, Kaasa A, McDonagh D, Stiles TC, Haraldseth O, Lereim I. Acute treatment of whiplash neck sprains injuries: A randomized trial of treatment during the first 14 days after a car accident. Spine 1998;23:25-31.

15. Thuile CH, Walzl M. Evaluation of electromagnetic fields in the treatment of pain in patients with lumbar radiculopathy or the whiplash syndrome. NeuroRehabilitation 2002;17:63-7.

16. Soderlund A, Lindberg P. An integrated physiotherapy/cognitivebehavioural approach to the analysis and treatment of chronic Whiplash Associated Disorders, WAD. Disabil Rehabil 2001;23:436-47.

17. Heikkila H, Astrom PG. Cervicocephalic kinesthetic sensibility in patients with whiplash injury. Scand J Rehabil Med 1996;28:133-8.

18. Krogstad BS, Jokstad A, Dahl BL, Soboleva U. Somatic complaints, psychologic distress, and treatment outcome in two groups of TMD patients, one previously subject to whiplash injury. J Orofac Pain 1998; 12:136-44.

19. Sterner Y, Lofgren M, Nyberg V, Karlsson AK, Bergstrom M, Gerdle B. Early interdisciplinary rehabilitation programme for whiplash associated disorders. Disabil Rehab 2001;23:422-9.

20. Vendrig AA, van Akkerveeken PF, McWhorter KR. Results of a multimodal treatment program for patients with chronic symptoms after a whiplash injury of the neck. Spine 2000;25:238-44.

21. Gennis P, Miller L, Gallagher EJ, Giglio J, Carter W, Nathanson N. The effect of soft cervical collars on persistent neck pain in patients with whiplash injury. Acad Emerg Med 1996;3:568-73.

22. Goodman R, Frew LJ. Effectiveness of progressive strength resistance training for whiplash: A pilot study. Physiother Can 2000;52:211-4.

23. Suter E, Harris S, Rosen M, Peterson D. Cervical spine adjustment improves muscle strength of upper extremities in patients with subacute whiplash. Eur J Chiropr 2002;49:107-8.

24. McCoy HG, McCoy M. A multiple parameter assessment of whiplash injury patients undergoing subluxation based chiropractic care: A retrospective study. J Vertebral Subluxation Res 1997;1:51-61.

25. Woodward MN, Cook JC, Gargan MF, Bannister GC. Chiropractic treatment of chronic "whiplash" injuries. Injury 1996;27:643-5. 


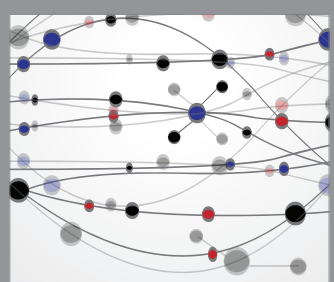

The Scientific World Journal
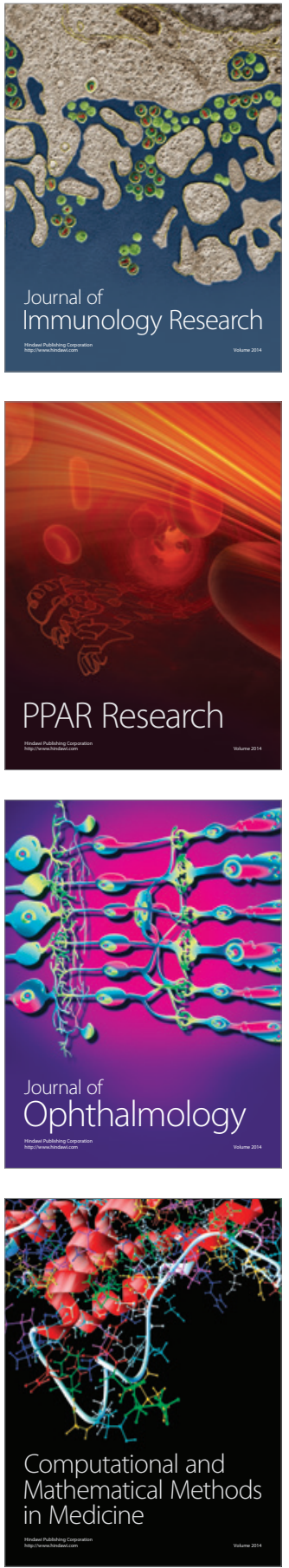

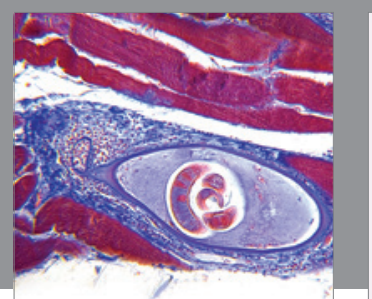

Gastroenterology Research and Practice

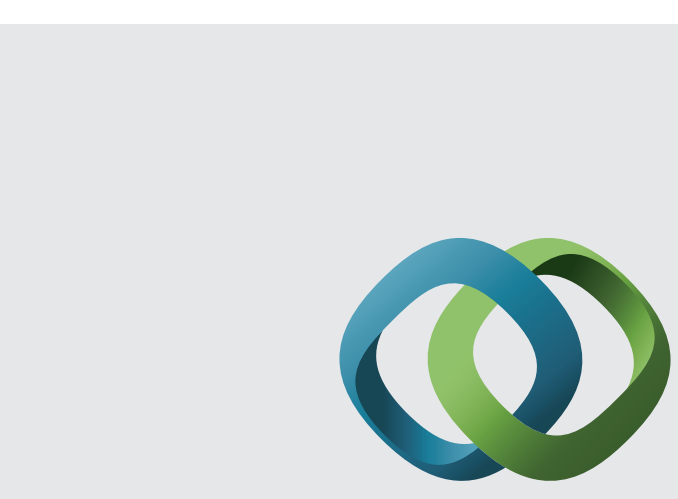

\section{Hindawi}

Submit your manuscripts at

http://www.hindawi.com
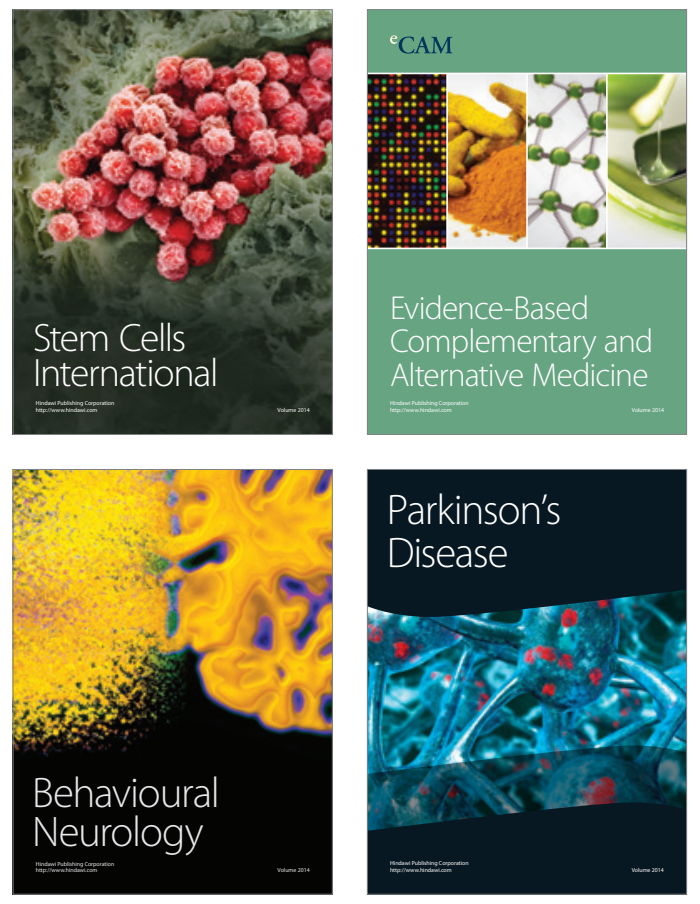
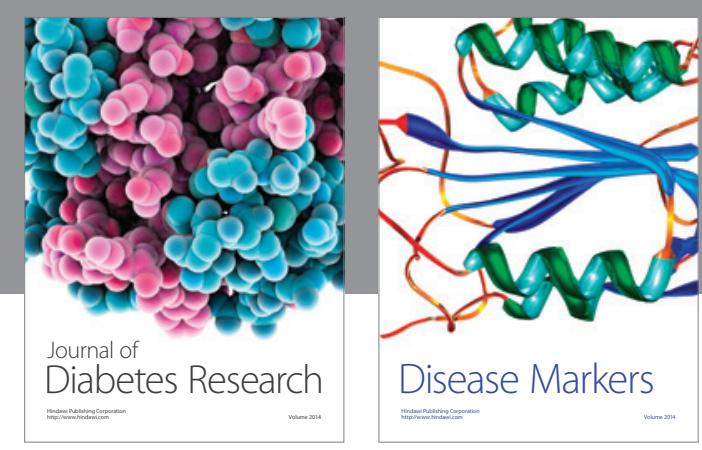

Disease Markers
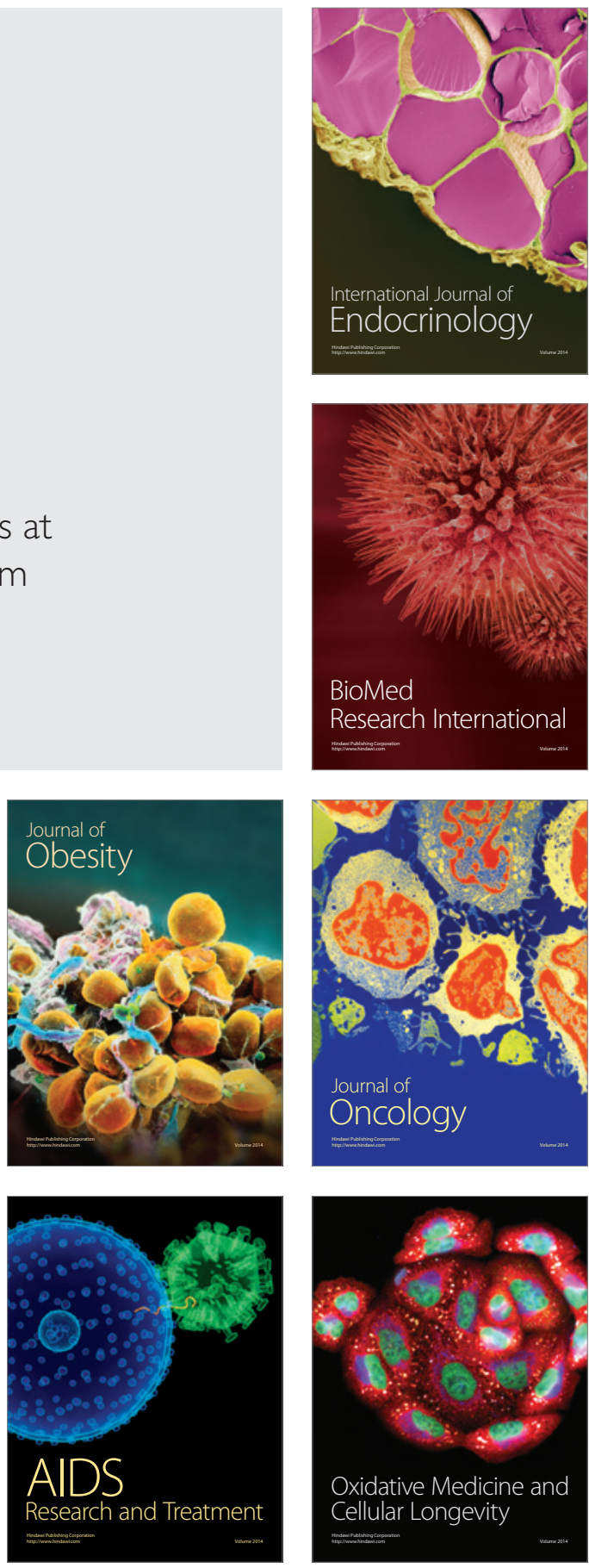